\title{
A Tri-Gold Triazolide with Long-Lived Luminescence
}

\author{
James E. Heckler, ${ }^{a}$ Bryce L. Anderson, ${ }^{b}$ and Thomas G. Gray* ${ }^{*}$,
}

${ }^{a}$ Department of Chemistry, Case Western Reserve University, 10900 Euclid Avenue, Cleveland Ohio 44106, U.S.A., and ${ }^{b}$ Department of Chemistry and Chemical Biology, Harvard University, Cambridge, Massachusetts 02138, U.S.A.

\begin{abstract}
We report the synthesis and characterization of tri-gold(I) complexes of a phenytriazolide ligand. This complex luminesces in solution at room temperature and $77 \mathrm{~K}$ with emission lifetimes of $4.72 \pm 0.8 \mu$ s at $298 \mathrm{~K}$ and $529 \pm 12 \mu$ s at $77 \mathrm{~K}$. Density-functional theory calculations on model complexes indicate that the triazolyl ring and aryl substituents approach coplanarity, and that total charge transfer is attenuated in the triplet excited state.
\end{abstract}

Keywords: gold; click chemistry; phosphorescence; cycloaddition; density-functional theory

Abbreviations: DFT, density-functional theory; HOMO, highest occupied Kohn-Sham orbital; LUMO, lowest unoccupied Kohn-Sham orbital

* Corresponding author.

E-mail address: tgray@ case.edu 
Introduction. Ligand-based cycloadditions of gold complexes have a venerable history. (Organophosphine)gold(I) azides react in [3 + 2]-cycloadditions with methylisonitrile to yield a $C$-bound tetrazolide,[1] with 1,1,1-trifluoroethanenitrile to afford an $\mathrm{N}$-bound tetrazolide,[2] and with carbon disulfide to form an azathiaheterocyclic complex, also $N$-bound. ${ }^{2}$ These discoveries anticipated the concept of click chemistry, which privileges reactions that combine high yields with operational ease and selectivity.[3-6] Certainly the leading click reaction is the coppercatalyzed [3 +2]-cycloaddition of organic azides to (mostly) terminal alkynes.[7] In its early days, practitioners of click chemistry concentrated on organic transformations; organometallic reactions that conform substantially to click standards emerged later.

(Phosphine)gold(I) azides were shown in 2007 to combine with terminal alkynes.[8] The resulting triazolides are metalated at carbon, despite a starting material aurated at nitrogen. The same study demonstrated the inverse reaction, where gold(I) alkynyls react with hydrazoic acid equivalents to yield the same triazolide complexes. With this protocol, gold has been attached to acetylinic dendrimers[9] and peptides.[10] Work thereafter revealed a copper-catalyzed reaction between non-hydrolyzable azides and gold(I) alkynyls.[11] This reaction proceeds with the 1,4regioselectivity of copper-catalyzed organic alkyne-azide cycloadditions. Subsequent research has widened the scope of metalla-click chemistry. Chan, Yam and co-workers[12] have described a luminescent platinum(II) triazolide prepared in a copper-catalyzed cycloaddition of the platinum alkynyl with an aryl azide. Fokin, Lin, Jia, and their co-workers[13] have reported ruthenium(II) alkynyls that react with organic azides to form triazolides. Lastra,[14] Lo,[15] Meggars,[16] and their respective collaborators have shown that (azido)ruthenium complexes add to alkynes and nitriles to afford cycloaddition products; Liu and co-workers have published similar results for molybdenum(II).[17] Mirica,[18] Schatzschneider,[19] and co-workers have 
published reactions of 3d-metal azides with alkynes; the resulting triazolides ligate through nitrogen. Szczepura and co-workers[20] have reacted azide-terminated $\left[\mathrm{Re}_{6} \mathrm{Se}_{8}\right]^{2+}$ species with electron-poor alkynes to form triazolides, thus demonstrating metalla-click reactivity of a metalmetal bonded cluster. Gladysz and co-workers[21] report copper-catalyzed reactions of platinum(II) polyynyls with benzyl azide; only terminal $-\mathrm{C} \equiv \mathrm{CH}$ moieties react. A later disclosure from the same group[22] considers click-type assemblies carrying multiple metal centers. Veige and co-workers have published a series of reports on reactions ("iClick") of azidometal reagents and gold(I) alkynyls to yield triazoles metalated at nitrogen and carbon.[23,24] As metalla-click chemistry unfolds,[25] metal triazolides with remarkable properties are being discovered. For example, we have identified a monogold triazolide that emits triplet phosphorescence with a 19-ms lifetime at 77 K.[26]

Reported here are triazolides where three gold(I) centers attach through $\sigma$-bonds: one to carbon and two to nitrogen. These complexes luminesce with microsecond-length radiative lifetimes at $77 \mathrm{~K}$ and $298 \mathrm{~K}$. To our knowledge, they are the first triaurated triazolides. They illustrate an advantage of gold(I): with its propensity for linear two-coordination, gold can bind at multiple sites on organic frameworks with minimal steric hindrance.

Results and Discussion. Tri-gold triazolide complexes assemble as in Scheme 1. One equivalent each of (triphenylphosphine)gold(I) azide and the corresponding alkynyl and triflimidate are added to diethyl ether in moist air, and stirred at room temperature with exclusion of light. Products are isolated in near-quantitative yields by filtration. 


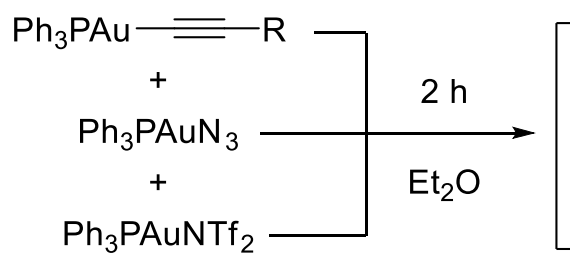

Scheme 1.

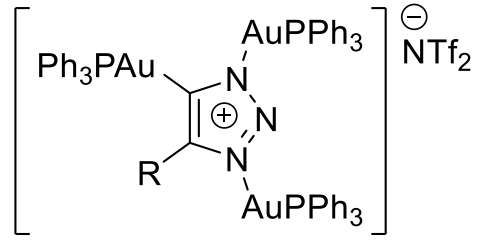

$\mathrm{R}=\mathrm{Ph}, 1$

$\mathrm{R}=$ 1-naphthyl, 2

Compound $\mathbf{1}$ is off-white or yellow as a solid, whereas $\mathbf{2}$ is red. Solutions of $\mathbf{1}$ are pale gold; those of $\mathbf{2}$ are orange. Absorption and emission spectra appear as Figure 1. Absorption sets in near $400 \mathrm{~nm}$ and rises sharply at wavelengths below $300 \mathrm{~nm}$. Ultraviolet-light excitation elicits broad, featureless emission that maximizes at $543 \mathrm{~nm}$ in 2-methyltetrahydrofuran solution. This emission quenches on exposure to atmospheric oxygen. The radiative lifetime of $\mathbf{1}$ is $4.72 \pm$ $0.8 \mu \mathrm{s}$ at room temperature and $529 \pm 12 \mu \mathrm{s}$ at $77 \mathrm{~K}$. For compound 2, emission lifetimes are $10.3 \pm 1.9 \mu$ s at $298 \mathrm{~K}$ and $6990 \pm 261 \mu$ s at $77 \mathrm{~K}$. The long luminescence lifetime and large apparent Stokes shifts (> $200 \mathrm{~nm}$ for 2, Figure 1(b)) suggests phosphorescence from a spin-triplet excited state. The structured emission near $370 \mathrm{~nm}$ for $\mathbf{2}$ is tentatively assigned as a ligandcentered fluorescence. Such dual luminescence has been encountered previously for (triazolyl)and (aryl)gold(I) species. ${ }^{11}$ 
(a)

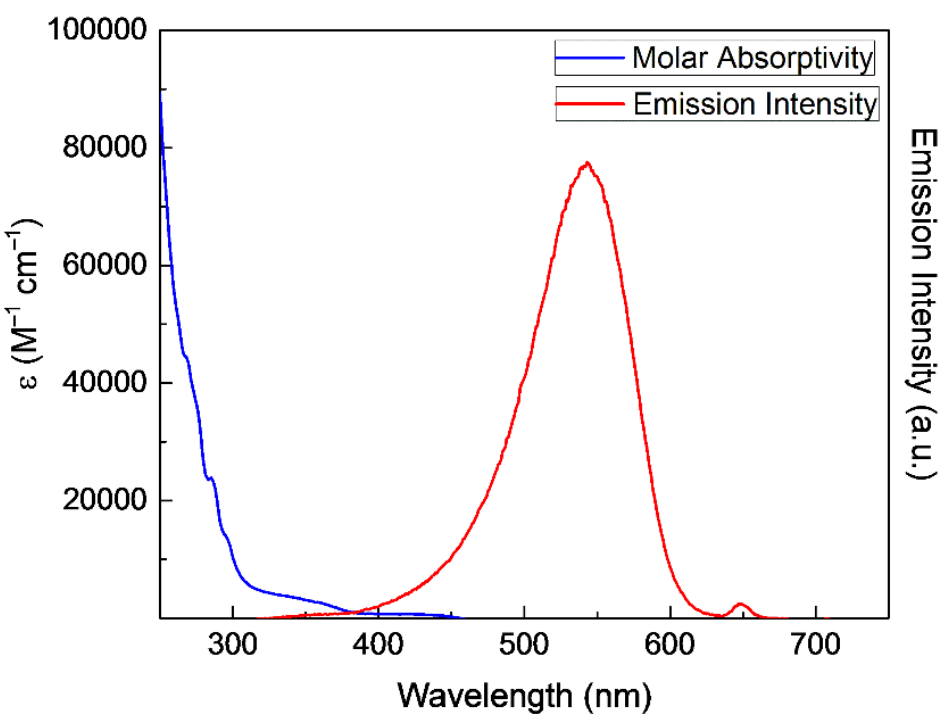

(b)



Figure 1. Absorption (blue) and emission (red) spectra (298 K) in 2-methyltetrahydrofuran solution: (a) 1, and (b) 2 . 
Density-functional theory calculations were carried out on $\mathbf{1}^{\prime}$ and $\mathbf{2}^{\prime}$ where methyl groups on phosphorus replace phenyls for computational tractability. Computations employed the parameter free PBE0 hybrid functional, which we have used earlier in studies of the ultrafast spectroscopy of gold(I) aryls.[27,28] Calculations of the ground-state singlets are spinrestricted; those of triplets, unrestricted. Harmonic vibrational calculations indicate the converged singlet and triplet structures to be minima of their respective potential energy hypersurfaces. Optimized metrics for both spin states are closely similar except for the dihedral angle between the triazolyl and the adjacent phenyl ring. The converged structures of tripletstate $\mathbf{1}^{\prime}$ and $\mathbf{2}^{\prime}$ appear as Figure 2, along with calculated metrics. For comparison, optimized ground-state structures are depicted in Figure S1, Supporting Information. In the triplet structure of $\mathbf{1}^{\prime}$, the triazolyl and phenyl rings are almost perfectly coplanar. In the ground state, the dihedral angle between best-fit planes is $1.7^{\circ}$. That is, conjugation between aromatic rings increases in the excited state. The calculated $\mathrm{C}_{\text {triazolyl }}-\mathrm{C}_{\text {phenyl }}$ bond distance shrinks $0.086 \AA$ on exciting from the ground to the triplet state. Moreover, the triplet structure shows bond length alternation suggesting quinoidal character, consistent with increased conjugation within the aromatic system, vide supra. The calculated structure of triplet $\mathbf{2}^{\prime}$ is also planarized compared to the ground-state structure. Ring dihedral angles are calculated to be $63.8^{\circ}$ in the ground state and $40.2^{\circ}$ in the triplet. 
(a)

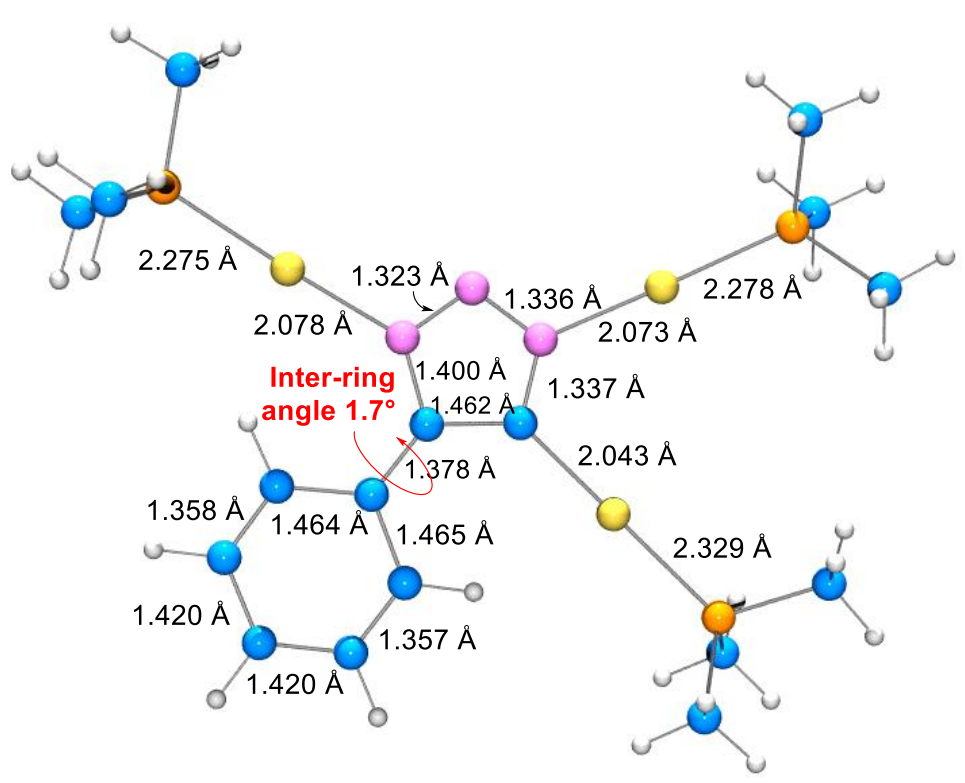

(b)

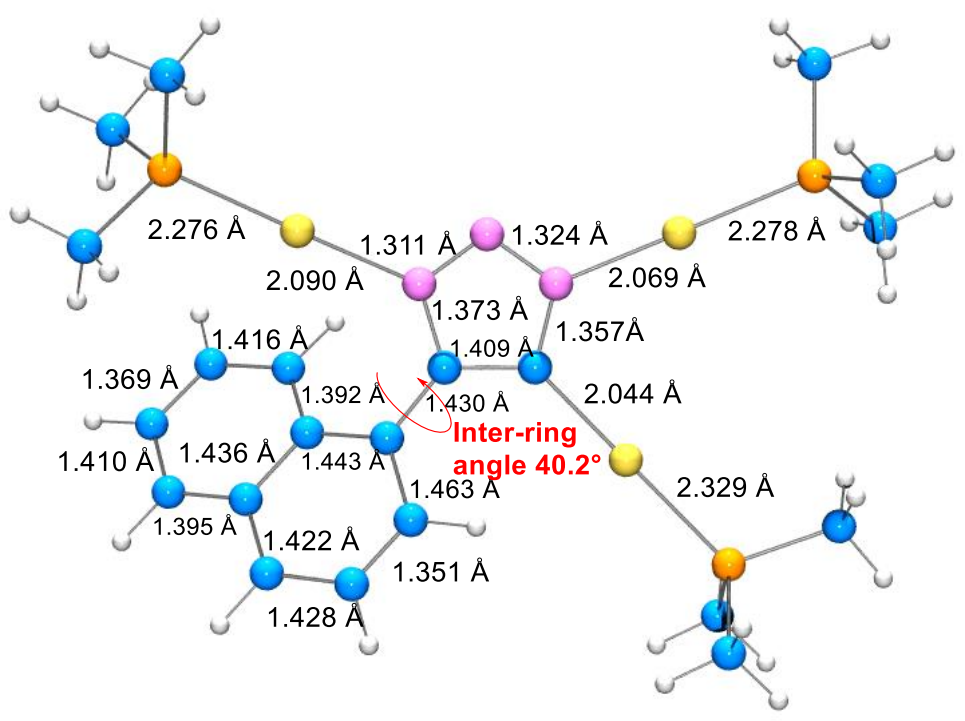

Figure 2. Optimized triplet-state geometries: (a) $\mathbf{1}^{\prime}$ and (b) 2'. Selected interatomic distances are indicated, as are torsional angles between rings. 
Figure 3(a) depicts a fragment orbital energy level diagram derived from a spinunrestricted calculation of ${ }^{3} \mathbf{1}^{\prime}$. In this diagram, energy levels of ${ }^{3} \mathbf{1}^{\prime}$ are correlated with those of the triplet ligand fragment and the singlet (trimethylphosphine)gold(I) cations. The singly occupied HOMOs reside almost wholly on the conjugated ligand (where HOMO is highest occupied Kohn-Sham orbital). Spin- $\alpha$ orbitals are plotted as Figure 3(b). The orbital energy level diagram of ${ }^{3} \mathbf{2}^{\prime}$, which is similar, appears as Figure S3, Supporting Information. A timedependent DFT calculation on the optimized structure of ${ }^{3} \mathbf{1}^{\prime}$ finds that the first triplet state consists $(>97 \%)$ of a one-particle transition between the HOMO and LUMO of the electronic ground state. This triplet state can be considered as the union of three singlet (trimethylphosphine)gold(I) cations with a triplet phenyltriazolide dianion. The first triplet of $\mathbf{2}^{\prime}$ is similar, consisting $(97 \%)$ of a LUMO $\leftarrow \mathrm{HOMO}$ transition from the ground state (in the calculated geometry of the triplet).

A Dapprich-Frenking charge decomposition analysis[29] finds that 0.75 electrons are transferred from the triazolide to the three (phosphine)gold(I) fragments in ground-state $\mathbf{1}^{\prime}$, whereas the net charge transfer for ${ }^{3} \mathbf{1}^{\prime}$ is 0.07 e in the other direction $(0.17$ spin- $\alpha$ electrons from (phosphine)gold(I) to triazolide; 0.10 spin- $\beta$ electrons from triazolide to (phosphine)gold(I)). For model $2^{\prime}$, charge transfer is $1.60 \mathrm{e}^{-}$(triazolyl to (phosphine)gold(I)) in the ground state and $0.10 \mathrm{e}^{-}$((phosphine)gold(I) to triazolyl) in the triplet excited state. For both complexes, the emitting excited state is mainly ligand-centric, and total charge transfer between fragments attenuates in the triplet state. 
(a)

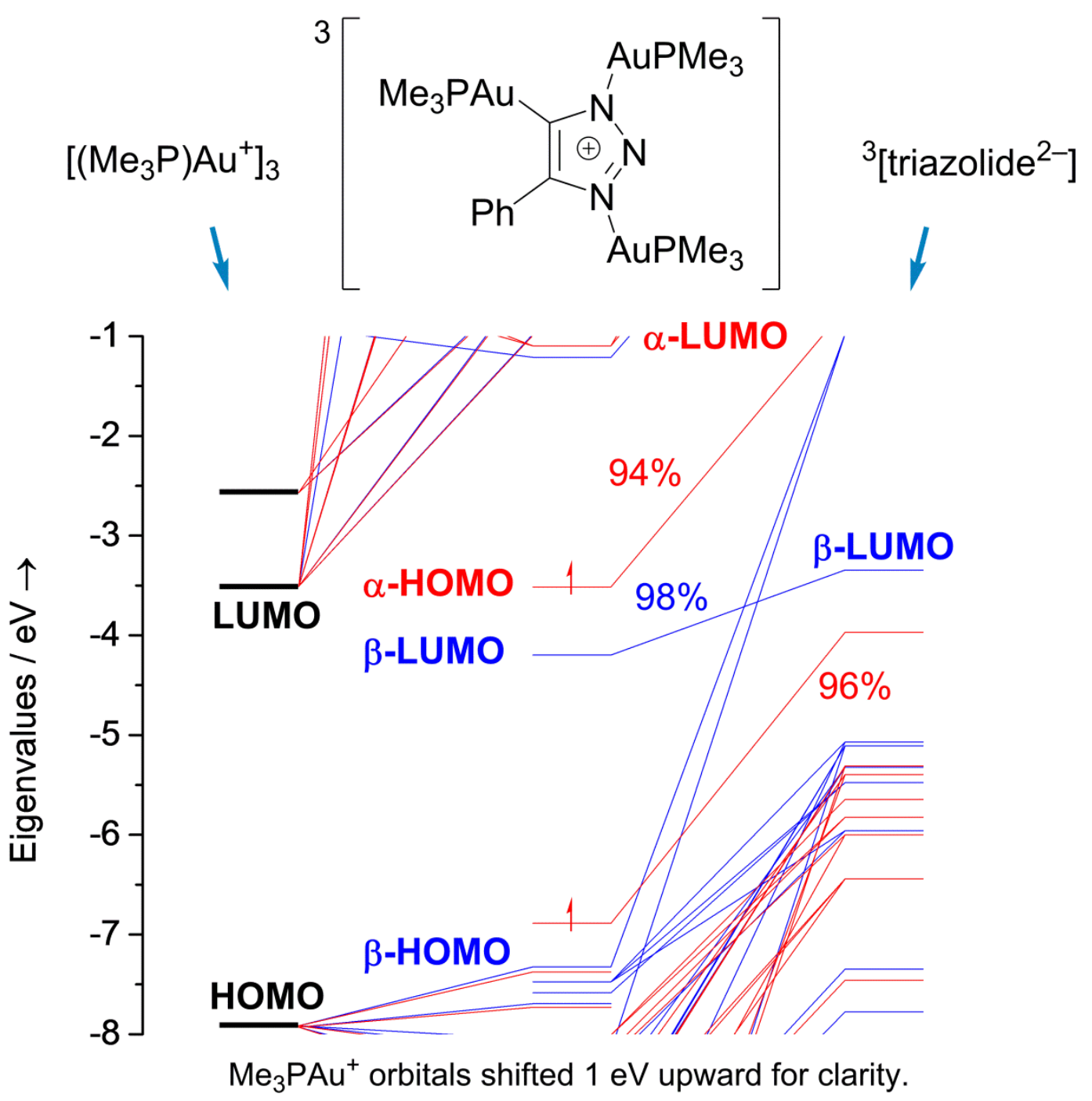

(b)
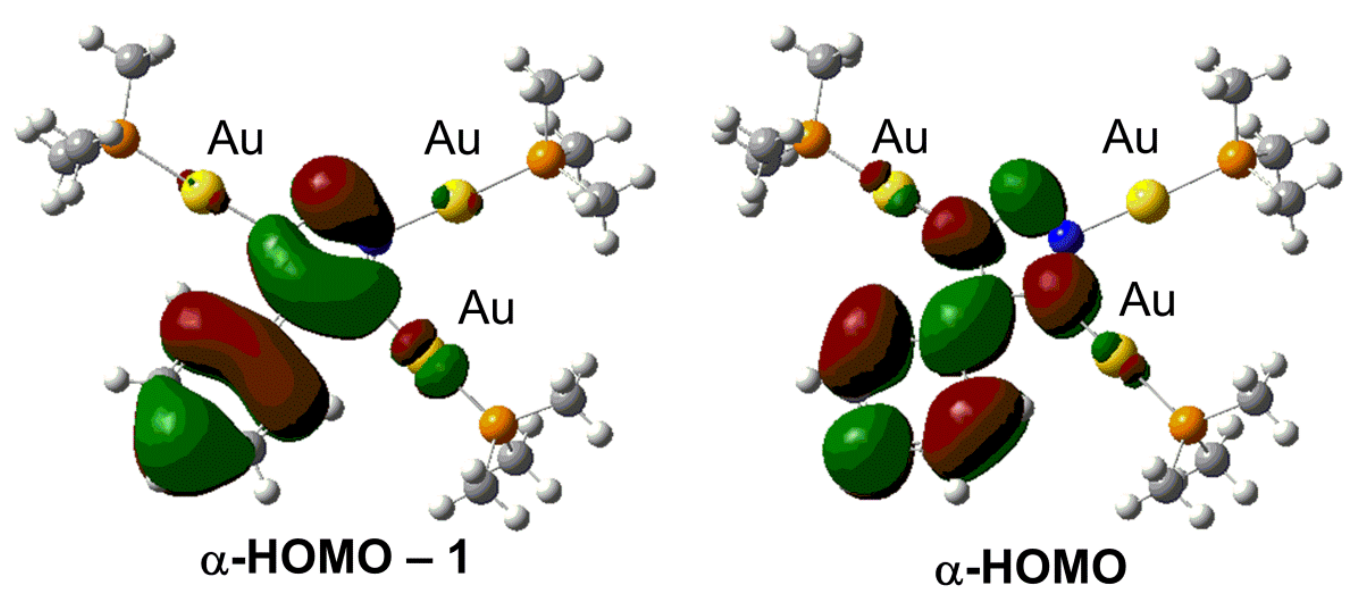

Figure 3. (a) Partial Kohn-Sham orbital energy level diagram of ${ }^{3} \mathbf{1}^{\prime}$ indicating compositions of selected orbitals. Percentages are of electron density. (b) Plots of selected spin- $\alpha$ orbitals (contour level 0.03 a.u.). 
Conclusions. In summary, we have shown that tri-gold(I) triazolyls self-assemble in one-pot reactions of (organophosphine)gold(I) alkynyls with the corresponding (phosphine)gold(I) azide and (phosphine)gold(I) triflimidate. This reaction resembles the inorganic click ("iClick") reactions investigated by Veige and others.[18,19,23,24] Earlier work[11] has demonstrated that gold binds selectively to nitrogen rather than to another gold in a three-center interaction.[30-36] The tri-gold product is luminescent with microsecond emission lifetimes at 77 and $298 \mathrm{~K}$. An emitting triplet state is indicated despite a lack of structure in the emission profile.

The excited-state lifetime of naphthyl derivative $\mathbf{2}$ is notably longer than that of phenyl analogue 1. Long phosphorescence lifetimes of gold(I) naphthyl triazolides have been encountered previously.[11] A study of the ultrafast photophysics of (phosphine)gold(I)substituted naphthalenes is available. The energetic isolation of the first triplet state gives rise to significant triplet lifetimes and to non-equilibrium excited-state dynamics.[28]

Geometry optimization finds that the aromatic rings of the aryl triazolyl ligand are coplanar in the first triplet excited state. Singly occupied orbitals are delocalized over this planar ligand framework. We expect that the one-pot reaction described here is a general path to longlived triplet phosphors. Further study of these compounds is in progress.

\section{Experimental}

\section{Materials and Methods}

All reactions were performed in air without any special precautions to exclude air or moisture. Toluene (HPLC grade) and pentane (HPLC grade, submicron filtered) were purchased from Fisher Scientific and used as received. (Triphenylphosphine)gold(I) 
[bis(trifluoromethyl)sulfonyl]imidate $\left(\mathrm{Ph}_{3} \mathrm{PAuNTf}_{2}\right)$ was purchased from Strem Chemicals and used as received. (Phosphine)gold(I) alkynyls[37] and azides ${ }^{8}$ were prepared as previously described. Caution: Appropriate precautions should be taken in all work involving metal azide complexes.

Deuterated solvents $\left(\mathrm{CDCl}_{3}\right)$ were obtained from Cambridge Isotope Laboratories and passed over activated basic alumina and distilled over activated $4 \AA$ sieves prior to use. ${ }^{1} \mathrm{H}$ NMR experiments were performed on a Varian-400 FT NMR spectrometer operating at $399.7 \mathrm{MHz}$. ${ }^{13} \mathrm{C}$ and ${ }^{31} \mathrm{P}\left\{{ }^{1} \mathrm{H}\right\}$ NMR experiments were performed on a Bruker Ascend-500 FT NMR spectrometer operating at 125.7 and $202.4 \mathrm{MHz}$, respectively. Chemical shifts are reported in parts per million $(\delta)$, measured from tetramethylsilane $(0 \mathrm{ppm})$ and referenced to the residual solvent peaks. UV-Vis absorption and luminescence experiments were performed on a Cary 5G UV-Vis-NIR spectrometer and Cary Eclipse spectrometer, respectively. Combustion analyses were performed by Robertson Microlit Laboratories (Ledgewood, NJ) or Midwest Microlab, LLC (Indianapolis, IN).

\section{Synthesis}

1,3,5-tris $\left(\mathbf{P h}_{3} \mathbf{P A u}\right)$-4-phenyl-1,2,3-triazolium triflimide (1). Into a $20 \mathrm{~mL}$ disposable vial was charged $\mathrm{Ph}_{3} \mathrm{PAu}$ (phenylethynyl) (118.2 mg, $0.2109 \mathrm{mmol}$ ), $\mathrm{Ph}_{3} \mathrm{PAuN}_{3}(105.0 \mathrm{mg}, 0.2095 \mathrm{mmol}$ ) and $\mathrm{Ph}_{3} \mathrm{PAuNTf}_{2}(156.2 \mathrm{mg}, 0.2113 \mathrm{mmol}$ ). The solids were suspended in $4 \mathrm{~mL}$ of diethyl ether and the mixture stirred for $3 \mathrm{~h}$. After $1 \mathrm{~h}$, the mixture had homogenized. The golden solution was evaporated to give a yellow residue. Trituration with hexanes liberated a golden-yellow powder which was collected by filtration and dried in vacuo. Golden powder. Yield: $307.4 \mathrm{mg}$ (81\%). m.p. $>120{ }^{\circ} \mathrm{C}$ dec. ${ }^{1} \mathrm{H}$ NMR: $\delta 8.15(\mathrm{~d}, 1 \mathrm{H}, J=2.5 \mathrm{~Hz}), 7.65-7.26\left(\mathrm{~m}, 49 \mathrm{H}, \mathrm{Ph}_{3} \mathrm{P}+\right.$ phenyl) 
${ }^{13} \mathrm{C}\left\{{ }^{1} \mathrm{H}\right\}$ NMR: $\delta 172.1\left(\mathrm{C}_{\text {aryl }}\right), 171.1\left(\mathrm{C}_{\text {aryl }}\right), 152.4\left(\mathrm{C}_{\text {aryl }}-\mathrm{Au}\right) \cdot{ }^{31} \mathrm{P}\left\{{ }^{1} \mathrm{H}\right\}$ NMR: $\delta 43.5$ (s, $1 \mathrm{P}, 33$ \%), 31.3 (br s, 2 P, $66 \%$ ). Anal. Calcd for $\mathrm{C}_{64} \mathrm{H}_{50} \mathrm{Au}_{3} \mathrm{~F}_{6} \mathrm{~N}_{4} \mathrm{O}_{4} \mathrm{P}_{3} \mathrm{~S}_{2}: \mathrm{C}, 42.68 ; \mathrm{H}, 2.80 ; \mathrm{N}, 3.11$. Found: C, 42.94; H, 2.91; N, $3.04 \%$ UV (2-MeTHF) $\lambda_{\max }, \mathrm{nm}\left(\varepsilon, \mathrm{M}^{-1} \mathrm{~cm}^{-1}\right): 268$ (sh, 24000$)$, 275 (sh, 18 600). Emission (2-MeTHF): $\lambda_{\mathrm{em},}$ nm: 543.

1,3,5-tris(Ph $\mathbf{3} \mathbf{P A u})$-4-(1-naphthyl)-1,2,3-triazolium triflimide (2). Into a $20 \mathrm{~mL}$ disposable vial was charged $\mathrm{Ph}_{3} \mathrm{PAu}\left(1\right.$-naphthyethynyl) (78.4 mg, $0.1284 \mathrm{mmol}$ ), $\mathrm{Ph}_{3} \mathrm{PAuN}_{3}$ (64.3 mg, $0.1283 \mathrm{mmol})$ and $\mathrm{Ph}_{3} \mathrm{PAuNTf}_{2}(94.8 \mathrm{mg}, 0.1282 \mathrm{mmol})$. The solids were suspended in $4 \mathrm{~mL}$ of diethyl ether and the mixture stirred for $4 \mathrm{~h}$. After $0.5 \mathrm{~h}$, the mixture had homogenized. After $4 \mathrm{~h}$, a powder had precipitated. The mixture was diluted with pentane and centrifuged. The supernatant was removed by pipette and the centrifuge process repeated. The resulting pale orange solid was dried in vacuo. Pale red-orange powder. Yield: $213.1 \mathrm{mg}(90 \%)$. m.p. $>132{ }^{\circ} \mathrm{C}$ dec. ${ }^{1} \mathrm{H}$ NMR: $\delta 8.34$ (d, 1H, $\left.J=4.0 \mathrm{~Hz}\right), 7.99$ (d, 1H, $\left.J=4.0 \mathrm{~Hz}\right), 7.94(\mathrm{~d}, 1 \mathrm{H}, J=4.0 \mathrm{~Hz}), 7.87$ (d, $1 \mathrm{H}, J=3.0 \mathrm{~Hz}), 7.65-7.02\left(\mathrm{~m}, 48 \mathrm{H}, \mathrm{Ph}_{3} \mathrm{P}+1\right.$-naphthyl). ${ }^{13} \mathrm{C}\left\{{ }^{1} \mathrm{H}\right\}$ NMR: $\delta 174.3\left(\mathrm{C}_{\text {aryl }}\right)$, $173.2\left(\mathrm{C}_{\text {aryl }}\right), 150.0\left(\mathrm{C}_{\text {ary }} \vdash \mathrm{Au}\right) .{ }^{31} \mathrm{P}\left\{{ }^{1} \mathrm{H}\right\}$ NMR: $\delta 43.1$ (s, $\left.1 \mathrm{P}, 33 \%\right), 31.5$ (br s, $2 \mathrm{P}, 66 \%$ ). Anal. Calcd for $\mathrm{C}_{68} \mathrm{H}_{52} \mathrm{Au}_{3} \mathrm{~F}_{6} \mathrm{~N}_{4} \mathrm{O}_{4} \mathrm{P}_{3} \mathrm{~S}_{2} \cdot \mathrm{C}_{4} \mathrm{H}_{10} \mathrm{O}$ : C, 44.92; H, 3.25; N, 2.91. Found: $\mathrm{C}, 45.00 ; \mathrm{H}, 3.03$; N, $2.87 \%$. UV (2-MeTHF) $\lambda_{\max }, \mathrm{nm}\left(\varepsilon, \mathrm{M}^{-1} \mathrm{~cm}^{-1}\right): 268$ (sh, 19 000), 276 (sh, 14500$), 287$ (8100). Emission (2-MeTHF): $\lambda_{\mathrm{em}, \mathrm{nm}}$ : 550, 590.

Acknowledgment. This work was supported by the U.S. Department of Energy, Office of Basic Energy Sciences, Division of Materials Science and Engineering, under Award DE-FG0213ER46977 to T. G. G. The nuclear magnetic resonance spectrometer at Case Western Reserve was funded by the U.S. National Science Foundation, NSF MRI-1334048. 


\section{References}

[1] W. Beck, K. Burger, W.P. Fehlhammer, Chem. Ber. 104 (1971) 1816-1825.

[2] R.F. Ziolo, J.A. Thich, Z. Dori, Inorg. Chem. 11 (1972) 626-631.

[3] M. Meldal, C.W. Tornøe, Chem. Rev. 108 (2008) 2952-3015.

[4] C.R. Becer, R. Hoogenboom, U.S. Schubert, Angew. Chem. Int. Ed. Engl. 48 (2009) 4900-8.

[5] J.E. Moses, A.D. Moorhouse, Chem. Soc. Rev. 36 (2007) 1249-62.

[6] H.C. Kolb, M.G. Finn, K.B. Sharpless, Angew. Chem. Int. Ed. Engl. 40 (2001) 20042021.

[7] C.W. Tornøe, C. Christensen, M. Meldal, J. Org. Chem. 67 (2002) 3057-3064.

[8] D. V. Partyka, J.B. Updegraff, M. Zeller, A.D. Hunter, T.G. Gray, Organometallics 26 (2007) 183-186.

[9] T.J. Robilotto, D.S. Alt, H.A. von Recum, T.G. Gray, Dalton Trans. 40 (2011) 8083-5.

[10] S.D. Köster, H. Alborzinia, S. Can, I. Kitanovic, S. Wölfl, R. Rubbiani, I. Ott, P. Riesterer, A. Prokop, K. Merz, N. Metzler-Nolte, Chem. Sci. 3 (2012) 2062.

[11] D. V. Partyka, L. Gao, T.S. Teets, J.B. Updegraff, N. Deligonul, T.G. Gray, Organometallics 28 (2009) 6171-6182.

[12] Y. Li, D.P.-K. Tsang, C.K.-M. Chan, K.M.-C. Wong, M.-Y. Chan, V.W.-W. Yam, Chem. - A Eur. J. 20 (2014) 13710-13715.

[13] P.N. Liu, J. Li, F.H. Su, K.D. Ju, L. Zhang, C. Shi, H.H.Y. Sung, I.D. Williams, V. V. Fokin, Z. Lin, G. Jia, Organometallics 31 (2012) 4904-4915.

[14] S. Miguel-Fernández, S. Martínez de Salinas, J. Díez, M.P. Gamasa, E. Lastra, Inorg. Chem. 52 (2013) 4293-302.

[15] T.-H. Wang, F.-L. Wu, G.-R. Chiang, S.-T. He, Y.-H. Lo, J. Organomet. Chem. 774 (2014) 57-60.

[16] T. Cruchter, K. Harms, E. Meggers, Chemistry 19 (2013) 16682-9.

[17] F.-C. Liu, Y.-L. Lin, P.-S. Yang, G.-H. Lee, S.-M. Peng, Organometallics 29 (2010) 4282-4290. 
[18] E. Evangelio, N.P. Rath, L.M. Mirica, Dalt. Trans. 41 (2012) 8010.

[19] L. Henry, C. Schneider, B. Mützel, P. V Simpson, C. Nagel, K. Fucke, U. Schatzschneider, Chem. Commun. (Camb). 50 (2014) 15692-5.

[20] S.A. Knott, J.N. Templeton, J.L. Durham, A.M. Howard, R. McDonald, L.F. Szczepura, Dalton Trans. 42 (2013) 8132-9.

[21] S. Gauthier, N. Weisbach, N. Bhuvanesh, J.A. Gladysz, Organometallics 28 (2009) 55975599 .

[22] M.C. Clough, P.D. Zeits, N. Bhuvanesh, J.A. Gladysz, Organometallics 31 (2012) 52315234 .

[23] X. Yang, S. Wang, I. Ghiviriga, K.A. Abboud, A.S. Veige, Dalt. Trans. 44 (2015) $11437-$ 11443.

[24] A.R. Powers, X. Yang, T.J. Del Castillo, I. Ghiviriga, K.A. Abboud, A.S. Veige, Dalton Trans. 42 (2013) 14963-6.

[25] T.J. Robilotto, N. Deligonul, J.B. Updegraff, T.G. Gray, Inorg. Chem. 52 (2013) 9659-68.

[26] J.E. Heckler, N. Deligonul, A.L. Rheingold, T.G. Gray, Chem. Commun. (Camb). 49 (2013) 5990-2.

[27] R.A. Vogt, T.G. Gray, C.E. Crespo-Hernández, (2012).

[28] R.A. Vogt, M.A. Peay, T.G. Gray, C.E. Crespo-Hernández, J. Phys. Chem. Lett. 1 (2010) $1205-1211$.

[29] S. Dapprich, G. Frenking, J. Phys. Chem. 99 (1995) 9352-9362.

[30] J.E. Heckler, M. Zeller, A.D. Hunter, T.G. Gray, Angew. Chem. Int. Ed. Engl. 51 (2012) $5924-8$.

[31] J. Schulz, E. Shcherbachenko, J. Roithová, Organometallics 34 (2015) 3979-3987.

[32] A.S.K. Hashmi, Acc. Chem. Res. 47 (2014) 864-76.

[33] A. Gómez-Suárez, S. Dupuy, A.M.Z. Slawin, S.P. Nolan, Angew. Chem. Int. Ed. Engl. 52 (2013) 938-42.

[34] K.A. Porter, A. Schier, H. Schmidbaur, Organometallics 22 (2003) 4922-4927.

[35] G. Seidel, C.W. Lehmann, A. Fürstner, Angew. Chem. Int. Ed. Engl. 49 (2010) 8466-70. 
[36] D. Weber, T.D. Jones, L.L. Adduci, M.R. Gagné, Angew. Chem. Int. Ed. Engl. 51 (2012) 2452-6.

[37] L. Gao, D. V. Partyka, J.B. Updegraff, N. Deligonul, T.G. Gray, Eur. J. Inorg. Chem. 2009 (2009) 2711-2719. 


\section{Graphical abstract.}

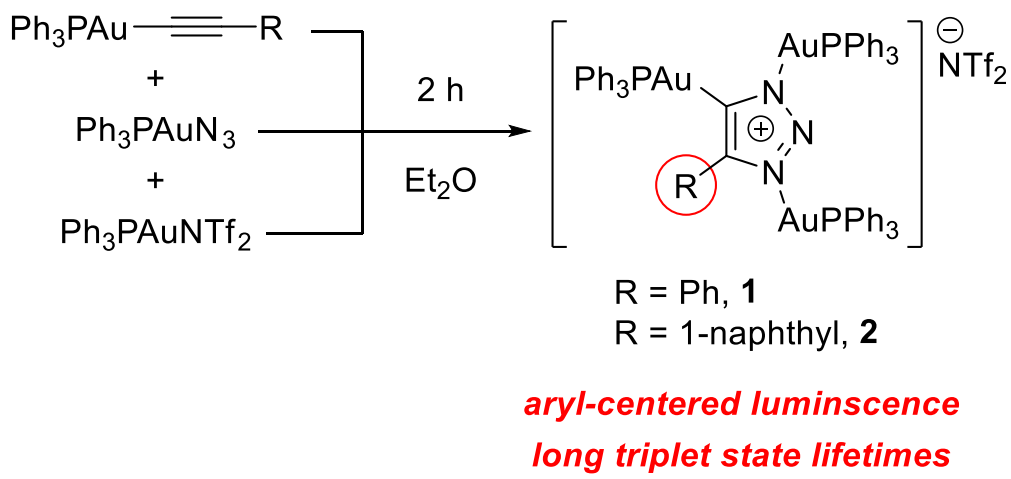

Triplet-state lumophores having long luminescent lifetimes are prepared in one-pot reactions that exemplify gold click chemistry. Emission spectra and time-dependent density-functional theory calculations indicate ligand-centered luminescence. 